\title{
Gastro-oesophageal reflux and respiratory function in infants with respiratory symptoms
}

\author{
F J Hampton, U M MacFadyen, C S Beardsmore, H Simpson
}

\begin{abstract}
This study aimed to define the incidence and severity of gastro-oesophageal reflux (GOR), as measured using 24 hour oesophageal pH monitoring, in 38 infants with recurrent respiratory symptoms and to relate these findings to measures of respiratory function. Twenty one infants had a pH under 4 for more than $5 \%$ of the time (one definition of abnormal GOR) and nine had GOR exceeding age related normal values. Maximum expiratory flow at functional residual capacity was reduced in 37 infants, airways resistance was raised in 19 infants, and thoracic gas volume was abnormal in 11 infants.

There was no association between indices of GOR and measures of lung function whether assessed by correlation or by $\chi^{2}$ analysis for normal versus abnormal values. However, individual infants appeared to have respiratory symptoms produced by GOR. This suggests that host responsiveness to GOR may be of greater relevance than the amount of GOR.
\end{abstract}

Gastro-oesophageal reflux (GOR) is sometimes regarded as a key underlying cause of recurrent and chronic respiratory symptoms, both in adults $^{1-3}$ and in children. ${ }^{4-16}$ In infants GOR might be relatively more important as posseting is common, ${ }^{17}$ and the effect of conventional bronchodilator treatment on cough and wheeze is unimpressive. ${ }^{18} 19$ Surprisingly few previous studies addressing the association between GOR and respiratory symptoms have been restricted to infancy. ${ }^{7}$ Information about the frequency of the association between the two and the nature of any possible cause and effect relationship remains incomplete.

In many studies patients have been selected on the basis of a history compatible with GOR, a poor response to treatment, or anomalies in their clinical course such as frequent episodes of lung collapse or consolidation on chest radiography. These series have included children with a range of respiratory disorders making it difficult to reach precise conclusions. We have tried to minimise potential bias by selecting infants presenting with recurrent or chronic respiratory symptoms that were not caused by readily definable lung disease, such as bronchopulmonary dysplasia or cystic fibrosis, and without the imposition of other restrictions. We postulated that, were the association of respiratory symptoms and GOR confirmed, objective indices of respiratory and GOR severity would be directly related. We therefore aimed to determine the incidence and severity of GOR and of respiratory function abnormalities in this group and to investigate a possible association between them.

\section{Patients and methocis \\ CASE SELECTION}

All infants aged less than 16 months presenting as general practitioner referrals to the paediatric outpatient department or admitted to hospital with cough and/or wheeze were considered for the study. The cough or wheeze was either chronic (over six weeks) or recurrent (each episode lasting longer than one week or occurring more than once a month). The study was approved by the ethical committee of the Leicestershire Health Authority. Exclusion criteria included mechanical ventilation in the newborn period, previous thoracic operations, or discovery of an underlying disorder on investigation (other than GOR). Investigations were performed as clinically indicated and no patients were found to have tuberculosis, cystic fibrosis, cardiac disease, or an immunocompromising disorder. One patient was excluded on account of a severe debilitating neurological disorder from which he subsequently died. Several potentially eligible infants were not included as their parents declined the invitation to participate in the study on the grounds that their children had relatively mild symptoms. Forty infants began the study but two were withdrawn when they removed the $\mathrm{pH}$ probe after a few hours and their parents did not wish it to be replaced.

The final study group from whom full data were available comprised 38 infants, 21 boys and 17 girls, aged 3 to 15 months, mean age 8 months. Three had been born prematurely but had not been ventilated. Table 1 summarises their clinical and radiography findings. Most had wheezing as their major symptom. In seven cases the first episode of wheezing occurred during acute bronchiolitis (when they were positive for respiratory syncitial virus). In six others bronchiolitis appeared to be the initial illness but virological data were not available. All infants had at least one chest radiograph and when clinically indicated some had further films taken. A single abnormal radiograph was seen in 11 infants, patchy collapse or consolidation in seven, and diffuse peribronchial thickening in four; two other infants had recurrent episodes of consolidation confirmed on radiography. Twenty four infants had a family history of atopic disorders (asthma, hay fever, eczema) in first degree relatives. Smoking in the home was reported for 30 infants of whom 21 had also been exposed in pregnancy. 
Table 1 Classification of infants by history and findings on radiography

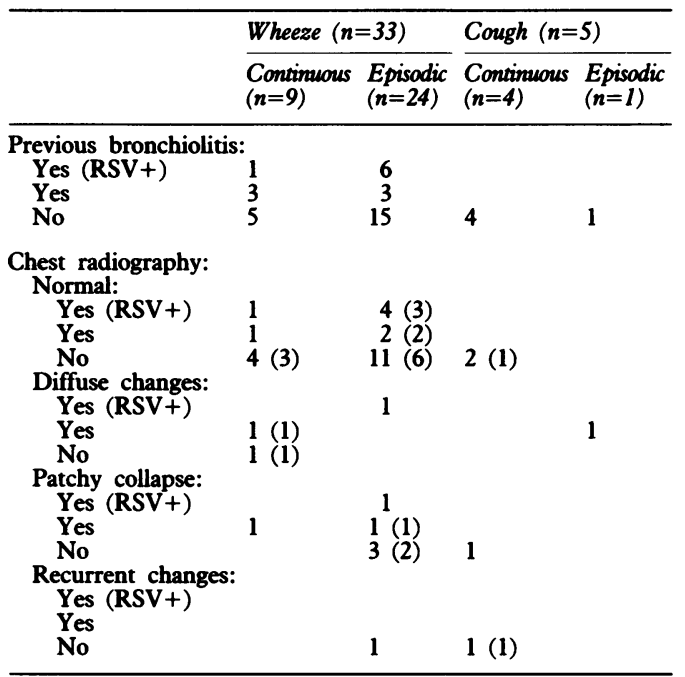

Figures in parentheses represent those with reflux index $>5 \%$. $\mathrm{RSV+}+$ positive for respiratory syncytial virus.

\section{MEASUREMENT OF GOR}

GOR was assessed with 24 hour oesophageal pH monitoring using the Synectics ambulatory system with semidisposable antimony monocrystant $\mathrm{pH}$ electrodes. The electrodes were placed pernasally to the middle third of the oesophagus as calculated from the infants' length ${ }^{20}$ and confirmed on chest radiography. An external sliver/ silver chloride reference electrode was placed on the chest. The pH was recorded every four seconds in a Digitrapper Mk 11 (Synectics) and transferred at the end of the study to an Amstrad PC 1512. Data analysis was carried out using dedicated software, 'EsopHogram' (Gastrosoft Inc).

The following reflux variables were measured using $\mathrm{pH}$ of under 4 to define reflux: the number of episodes, the number of episodes lasting longer than five minutes, the length of the longest episode in minutes, and the percentage of time with $\mathrm{pH}<4$, also called the 'reflux index' (RI). These were calculated for the total time, time excluding mealtimes, time less than 120 minutes after a meal, time greater than 120 minutes after a meal, and night time. Sleep state was not recorded and night was arbitrarily defined as $2200-0600$. All results were expressed per hour as there were differences in the duration of the studies. Additional reflux measures calculated were the median $\mathrm{pH}$ values for the whole study, day and night and also the mean duration of reflux episodes occurring at night.

In an attempt to compensate for presumed variation in GOR with age a score was devised based on the method of Johnson and Demeester ${ }^{21}$ and using the normal data of Vandenplas and Sacre-Smits. ${ }^{22}$ By this method a score of 4 represents the mean plus 2 SDs of the normal data and so can be said to represent the upper limit of normal. This score was calculated for all four reflux measures for the total time. As the normal range derived from the data of Vandenplas and Sacre-Smits is higher than other published normal values in children 23 an additional measure of 'normal' was used. By defining the upper limit of normal for the reflux index for the total time either as $\mathrm{RI}=5 \%$ or $\mathbf{R I}$ score $=4$, two overall results of normal or abnormal were given to each $\mathrm{pH}$ study.

During the $\mathrm{pH}$ studies parents and nurses were asked to note the timing and duration of any symptoms, particularly episodes of wheeze or cough.

\section{MEASUREMENT OF RESPIRATORY FUNCTION}

Assessment of respiratory function consisted of plethysmographic determination of thoracic gas volume and airways resistance ${ }^{25}$ and measurement of maximum expiratory flow at functional residual capacity (V்axFRC) using the squeeze technique. $^{26}$

Infants were sedated with chloral hydrate (100 mg/kg body weight) and once asleep were wrapped in an inflatable jacket extending from the neck to the thighs. A facemask with a pneumotachograph attached was applied around the nose and mouth using a ring of sterile putty to form an airtight seal. Respiratory flow was electronically integrated to provide a tidal volume signal and the flow-volume loop was displayed on an oscilloscope. At the end of a tidal inspiration the jacket was rapidly inflated by opening a three way tap connected to an air filled pressure reservoir. The resultant compression of the chest and abdomen caused a rapid expiration producing a partial forced expiratory flow-volume curve. Signals of respiratory flow, volume, and jacket pressure were recorded on a storage oscilloscope (Bodytest, Jaeger) and subsequently plotted at 1/4 speed onto a chart recorder. These signals were also stored on an Apple IIe microcomputer for later analysis. A minimum of $\mathbf{1 0}$ measurements was made in each infant over a range of applied jacket pressures up to a maximum of $80 \mathrm{~cm} \mathrm{H}_{2} \mathrm{O}$ $(7 \cdot 84 \mathrm{kPa})$. Recordings were inspected and only those technically acceptable were analysed. ${ }^{27}$ The final recorded value of $\dot{V} \max F R C$ was the highest value obtained from the flow-volume loops analysed.

When the squeezes were completed the jacket was loosened and the infant continued to sleep within the whole body plethysmograph. Thoracic gas volume measured according to the method of Dubois et $a l^{28}$ as modified for infants. ${ }^{29} \mathrm{~A}$ new face mask with an additional outlet to measure mouth pressure was applied and attached to a rebreathing apparatus via two pneumatically operated valves allowing the infant to breathe from either the plethysmograph or a heated rebreathing bag. After a brief period breathing warmed air-usually well within a minute - both valves were closed for a few seconds to produce total airway occlusion against which the infant made several respiratory efforts. The recorded signals of flow and plethysmographic and mouth pressures were stored both in the oscilloscope and on computer as above and used to calculate thoracic gas volume.

Airways resistance was measured from the recordings of flow and pressure taken from the period of quiet breathing before the airway 
occlusion for thoracic gas volume measurement. At least five representative breaths were chosen from the charted and computerised records to calculate airways resistance by conventional methods. ${ }^{28} 29$ Specific conductance was calculated by dividing the reciprocal of airways resistance (conductance) by thoracic gas volume.

Respiratory function tests were expressed as a percentage of previously published predicted values based on the infant's length. ${ }^{29} 30$ Thoracic gas volume was described as abnormal if it was over $120 \%$ or under $80 \%$ and very abnormal if over $140 \%$. Airways resistance was considered raised if over $120 \%$ and very high if over $200 \%$. Specific conductance was described as low if under $80 \%$ and very low if under $50 \%$. VmaxFRC was graded at less than $80 \%, 50 \%$, and $25 \%$.

\section{METHODS OF COMPARISON}

Each measure of GOR was compared with each measure of respiratory function using Pearson correlation. This was then repeated using only the results from infants with abnormal GOR. Then a series of $\chi^{2}$ tests for normal versus abnormal results was performed using both definitions of normal and abnormal for GOR. The $\chi^{2}$ tests were also performed with only the extreme lung function test results classified as abnormal. These multiple comparisons run a high risk of demonstrating apparently significant results by chance but as it was uncertain which of the values might be relevant it was felt that this was a suitable initial approach. Any result appearing significant in this way would have to be retested in a new study.

\section{Results}

Completed data for GOR variables and respiratory function measures were obtained for all 38 infants studied. Twenty one infants had abnormal GOR as defined by a reflux index over $5 \%$ and nine had a reflux index score more than 4 . The normal data of Vandenplas and Sacre-Smits included no infants aged $8 \cdot 5$ to 14 months ${ }^{22}$ so the four infants in this age range were compared with the group closest in age, in all cases the younger group. All had an RI score less than 4 in this comparison and so were called normal, although they scored more than 4 on values for the older group. Using the normal values of Vandenplas and Sacre-Smits 25 infants had at least one of the four variables which was abnormal.

Three infants had a large thoracic gas volume (all $>140 \%$ ) and eight a small one $(<80 \%)$. Nineteen infants had a high airways resistance $(>120 \%)$ and nine very high $(>200 \%)$. Results of VmaxFRC showed only one infant had a value $>79 \%$ predicted, 12 between 50 and $79 \%$, 14 between 25 and $49 \%$, and 11 under $25 \%$.

No correlations were found between any of the measures of reflux and any of the respiratory function test results whether the group as a whole was considered or only those with abnormal GOR. When using $\chi^{2}$ for normal versus abnormal values there was also no association observed (table 2).

Eleven infants had a median $\mathrm{pH}$ at night lower than that by day but their respiratory function tests did not differ from those of the other infants. Similarly there was no difference in respiratory function between the nine infants with an abnormal mean duration of reflux at night ( $>4$ minutes) as defined by Jolley $e t a l^{7}$ and the others.

Comparing the 13 infants with at least one abnormal chest radiograph with the 25 who only ever had a normal chest radiograph no differences in reflux variables were seen. The group with abnormal radiography had a higher thoracic gas volume, median $104 \%$ versus $86 \%$ ( $p=$ 0.01 ), but these medians are both within the normal range.

Differences in history were analysed using the Mann-Whitney test. Separating the infants by their family history of atopic disorders (one or more first degree relatives with asthma, eczema, or hay fever) revealed an unexpected difference in the amount of GOR. Fifteen of the 28 reflux variables analysed were significantly higher in the group with no family history of atopy. This is demonstrated in figs 1 and 2 for the RI and the RI score. The median RI in those with a family history of atopy was $4.7 \%$ and in those without $11 \cdot 7 \%(p=0.0004)$ and the $95 \%$ confidence intervals (CI) for the difference were 3 to $10 \cdot 8$. For the score the median value for those with a family history of atopy was $2 \cdot 2$ and for those without $4.6(p=0.0003)$ with $95 \% \mathrm{CI}$ for the difference being 0.9 to 2.9 . As seen in the figure the only abnormal RI scores are in the group without a family history of atopy.

No significant differences were found in respiratory function test results between the groups with and without a family history of atopy. Division by smoking exposure or history of bronchiolitis demonstrated no differences in either respiratory function or reflux variables.

The data on the timing of respiratory symptoms during the $\mathrm{pH}$ study was incomplete, largely because symptoms did not occur or were constant but possibly in some cases because they were not recorded. Two infants with variable symptoms had a strong temporal association between these and their GOR. The first had a family history of asthma and a normal $\mathrm{pH}$ study by all criteria $(\mathrm{RI}=2 \cdot 4 \%)$; wheezing was reported during all the brief episodes of reflux during her 24 hour study and she later develo-

Table 2 Results of respiratory function tests versus $p H$ studies

\begin{tabular}{|c|c|c|c|c|c|c|c|c|c|c|c|c|c|}
\hline & \multicolumn{3}{|c|}{ Thoracic gas volume } & \multicolumn{3}{|c|}{ Airways resistance } & \multicolumn{4}{|c|}{$\dot{V} \max F R C$} & \multicolumn{3}{|c|}{ Specific conductance } \\
\hline & Low & Normal & High & Normal & High & Very high & $<25 \%$ & $<50 \%$ & $<79 \%$ & Normal & Very low & Low & Normal \\
\hline $\begin{array}{l}\text { RI }>5 \% \\
\text { RI }<5 \% \\
\text { RI score }>4 \\
\text { RI score }<4\end{array}$ & $\begin{array}{l}5 \\
3 \\
2 \\
6\end{array}$ & $\begin{array}{r}16 \\
11 \\
7 \\
20\end{array}$ & $\begin{array}{l}\mathbf{0} \\
\mathbf{3} \\
\mathbf{0} \\
\mathbf{3}\end{array}$ & $\begin{array}{r}12 \\
7 \\
6 \\
13\end{array}$ & $\begin{array}{l}5 \\
5 \\
1 \\
9\end{array}$ & $\begin{array}{l}4 \\
5 \\
2 \\
7\end{array}$ & $\begin{array}{r}5 \\
6 \\
1 \\
10\end{array}$ & $\begin{array}{r}8 \\
6 \\
4 \\
10\end{array}$ & $\begin{array}{l}7 \\
5 \\
3 \\
9\end{array}$ & $\begin{array}{l}1 \\
0 \\
1 \\
0\end{array}$ & $\begin{array}{l}3 \\
7 \\
2 \\
8\end{array}$ & $\begin{array}{l}6 \\
3 \\
1 \\
8\end{array}$ & $\begin{array}{r}12 \\
7 \\
6 \\
13\end{array}$ \\
\hline
\end{tabular}




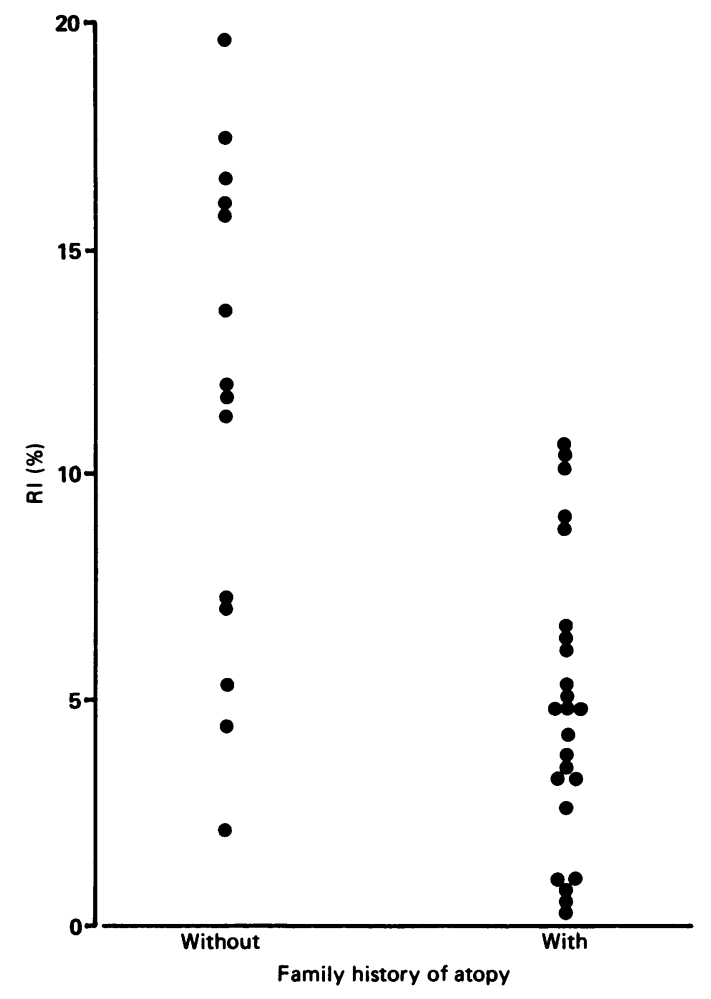

Figure 1 Reflux index (RI) for the total time in infants with and without a family history of atopy (upper limit of normal 5\%).

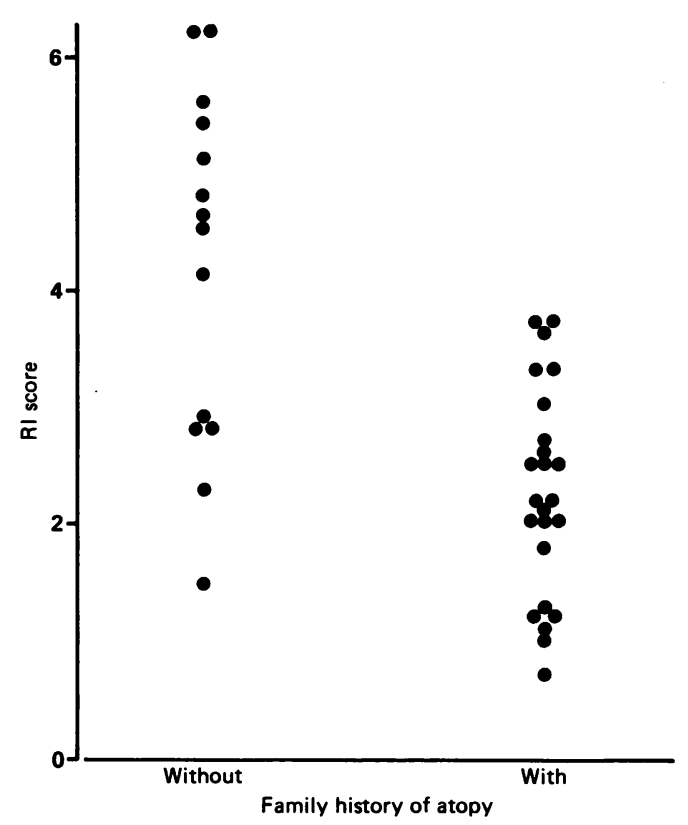

Figure 2 Reflux index $(R I)$ score in infants with and without a family history of atopy (upper limit of normal 4).

ped wheeze induced by acid fruit juice drinks. In the other infant, who also had a family history of atopy and who had moderately abnormal GOR $(R I=6 \%)$, reflux episodes were associated with periods of tachypnoea recorded by his mother. The first of these infants had abnormal airways resistance, specific conductance, and $\dot{V} \operatorname{maxFRC}$ and the second a low thoracic gas volume and reduced $\dot{V} \operatorname{maxFRC}$. A further infant, with no family history of atopy, appeared to have a link between GOR and respiratory symptoms. He had recurrent epi- sodes of consolidation on radiography and significant GOR ( $R I=11 \%$ ) but after having a Nissen's fundoplication he had no further episodes. His preoperative respiratory function tests were normal except for a VंmaxFRC of $53 \%$ of predicted. He developed perioperative respiratory syncytial virus bronchiolitis and his postoperative VmaxFRC was $25 \%$ of predicted.

\section{Discussion}

Previous studies of the association between GOR and respiratory disease have selected children with particularly severe symptoms, ${ }^{10} 11$ recurrent pneumonias suggestive of aspiration, ${ }^{4}$ appreciable nocturnal symptoms, ${ }^{16}$ or a combination thereof. ${ }^{913}$ Where these features have not been used for selection a broad age range of children has been studied. ${ }^{5}{ }^{14}$ In selecting patients for this study we had two aims, firstly to limit the age of the children investigated to under 18 months and secondly to include all infants with chronic or recurrent respiratory symptoms in whom a specific underlying disease had not been identified.

The results obtained from this group provide the opportunity to speculate on the role of GOR in a uniform group of infants with moderate 'disease'. Within this group nearly all the infants had abnormal respiratory function tests, which is not surprising as they were selected for respiratory symptoms. A proportion of the infants also had excessive GOR, 21 (55\%) had an RI of more than $5 \%$ and nine (24\%) had an RI score over 4 . Thus even when using the highest available normal values, more GOR occurred in this group than would be expected from a randomly selected group.

Exploring this association further, however, we found no relationship between the amount of acid GOR and the degree of abnormality of respiratory function tests. The pattern of GOR was also unrelated to respiratory function abnormalities. Jolley et al found that infants whose nocturnal reflux episodes had a mean duration of longer than four minutes had an improvement in their respiratory disease after surgery for GOR. ${ }^{7}$ This measure of GOR was not associated with more abnormal respiratory function tests in our study. Vandenplas et al found that infants with respiratory disease had a lower mean $\mathrm{pH}$ value at night than during the day. ${ }^{31}$ Using median $\mathrm{pH}$ values the 11 infants in this study whose median nocturnal $\mathrm{pH}$ was less than their daytime median did not have more severe respiratory function abnormalities than the others.

The differences we found in the amount of GOR between the infants with and without a family history of atopy are unlikely to have been due to chance as they occurred in 15 of the 28 variables and most were highly significant $(\mathrm{p}<0.01)$. Taking the $\mathrm{pH}$ study results in isolation, without considering respiratory function or clinical features, it appeared that there may have been two groups of infants with different underlying problems. Infants with a family history of atopy may have represented one group whose respiratory symptoms were partly determined by inherited factors, such as atopy or 
bronchial hyperreactivity, while the others represented a group in whom respiratory symptoms were more likely to have been due to GOR. However, within each of the two groups there was no correlation between the amount of reflux and the severity of respiratory dysfunction suggesting that there are other reasons for the differences in results. In addition the observation that wheezing may be temporally related to minimal GOR suggests that even normal amounts of reflux may underly respiratory symptoms in the presence of predisposing host factors.

In the three infants described in detail there was a clear clinical connection between GOR and respiratory symptoms but the results of $\mathrm{pH}$ studies and respiratory function tests were unrelated. The infant with recurrent consolidation and excessive reflux had only minimal respiratory function abnormalities while the other two had more severe lung function abnormalities and less GOR. The lack of association between measures of GOR and respiratory function in these three infants reflects that found in the group as a whole and raises the possibility that this may mask a true link between the two.

There are several possible explanations for this lack of association. Respiratory function test changes resulting from GOR may not be present at the time of the tests or may not be detected by the tests performed. Studies in adults and older children have found that mimicking GOR with acid infused into the oesophagus did not influence baseline lung function tests but only bronchial reactivity, which we did not measure. ${ }^{32-35}$ Another possibility is that the measurement of GOR was influenced by the confounding effect of nonacid GOR. In this study we only assessed acid GOR but aspiration of neutral stomach contents may be just as harmful and in dogs the vagal response to oesophageal distension is as strong as the response to acid perfusion. ${ }^{36}$

Even assuming that 24 hour oesophageal $\mathrm{pH}$ monitoring is an accurate reflection of GOR a causal link between GOR and respiratory symptoms could still be explained by postulating variation in the sensitivity of individuals to GOR. Some infants may have a highly tuned vagal reflex with an exaggerated effector response to a normal receptor stimulus. This may lead to excessive bronchoconstriction with even a normal amount of reflux. The infant whose wheeze coincided with her few episodes of GOR may exemplify this. In other infants the receptor response may be increased because of a sensitive oesophagus, either primary or secondary to oesophagitis. ${ }^{37}$ The occasional reports of a decrease in respiratory symptoms after treatment of GOR, even when this cannot be shown to be abnormal, ${ }^{13}$ might be explained in this way. Pharyngeal dysfunction is another possible explanation for respiratory disease caused by a normal amount of GOR and need not be severe enough to be clinically evident. While there may be more opportunity for aspiration to occur with more GOR the fate of the refluxed material when it reaches the pharynx may be more important and aspiration could occur with a single episode of reflux.
It was not possible to investigate the temporal link between GOR and respiratory symptoms in many infants as the times of more severe symptoms were not recorded. Parents were encouraged to make such recordings and discussion in most cases suggested that if changes had occurred they had been noted. It may be that the lack of such variation was because GOR was not inducing respiratory changes but it is also possible that the severity of respiratory dysfunction was such that changes were not clinically detectable. Previous studies have attempted to overcome this difficulty in demonstrating a causal role of GOR by treating it and recording the response of respiratory symptoms. Patients in such studies have shown symptomatic improvement, ${ }^{4} 57811131438$ but as described above these patients were usually highly selected and objective measures of respiratory function were not made.

It has been suggested that GOR may be a result of rather than a cause of respiratory symptoms with the increased pleural pressure swings associated with respiratory dysfunction provoking GOR. ${ }^{39}$ The absence of an association between respiratory function tests results and GOR is against this being important in most infants, with the provisos already discussed. Others have suggested that increased diaphragmatic work protects against GOR by increasing lower oesophageal sphincter pressure. ${ }^{40}$

Some different approaches to the study of the interaction of these two common problems might be employed in future. Acidifying the infants' feeds would avoid the failure of a $\mathrm{pH}$ study to detect neutral reflux episodes and use of a high oesophageal $\mathrm{pH}$ probe might be informative, as reflux to the upper oesophagus might be more closely related to respiratory problems. Refinement of techniques for detecting microaspiration would also be helpful as radioisotope milk scans seem to be insensitive ${ }^{41}$ and the presence of fat laden macrophages in tracheal aspirates seems to be non-specific. ${ }^{42}$ Autonomic dysfunction may also be a fruitful area for further study as it may be a common underlying cause for both GOR and respiratory disorders ${ }^{43}$ or GOR may cause abnormalities in autonomic function. ${ }^{44}$

In conclusion we have found excess GOR in a group of infants with respiratory symptoms, particularly those without a family history of atopy. However we have failed to demonstrate any association between the amount of GOR and the degree of respiratory dysfunction. Despite this there was clinical evidence of a link between the two problems in three infants and it remains possible that they are linked in more infants but that the techniques used have failed to demonstate this.

This work was supported by a grant from Janssen Pharmaceutical Limited. We would like to thank the paediatricians who referred infants under their care for investigation, the parents for agreeing to the investigations, and the parents and nursing staff for looking after the infants during the studies.

1 Mays EE. Intrinsic asthma in adults: association with gastroesophageal reflux. FAMA 1976;236:2626-8.

2 Mays EE, Dubois JJ, Hamilton GB. Pulmonary fibrosis associated with tracheobronchial aspiration. Chest 1976;69: $512-5$. 
3 Barish CF, Wu WC, Castell DO. Respiratory complications inch Intern Med 1985;145: of gast

4 Berquist WE, Rachelefsky GS, Kadden M, et al. Gastroesophageal reflux-associated recurrent pneumonia and chronic asthma in children. Pediatrics 1981;68:29-35. 5 Danus $\mathrm{O}$, Casar C, Larrain A, Pope CE. Esophageal refluxin children. $\mathcal{F}$ Pediatr 1976;89:220-4.

6 Euler AR, Byrne WJ, Ament ME, et al. Recurrent pulmonary disease in children: a complication of gastromonary disease in children: a complication

7 Jolley SG, Herbst JJ, Johnson DJ, Matlak ME, Book LS Esophageal $\mathrm{pH}$ monitoring during sleep identifies children with respiratory symptoms from gastroesophageal reflux. with respiratory symptoms from

8 Jolley SG, Herbst JJ, Johnson DJ, Matlak ME, Book LS. Surgery in children with gastroesophageal reflux and Surgery in children with gastroesophageal reflux

9 Baer M, Maki M, Nurminen J, Turjanmaa V, Pukander J, Vesikari T. Esophagitis and findings of long-term esophageal $\mathrm{pH}$ recording in children with repeated lower respiratory tract symptoms. F Pediatr Gastroenterol Nutr 1986;5: $187-90$

10 Christie DL, O'Grady LR, Mack DV. Incompetent lower esophageal sphincter and gastroesophageal reflux in acute pulmonary disease of infancy and childhood. $\mathcal{f}$ Pediat 1978;93:23-7.

11 Malfroot A, Vandeplas Y, Verlinden M, Piepsz A, Dab I. Gastroesophageal reflux and unexplained chronic respiratory disease in infants and children. Pediatr Pulmonol 1987; 3:208-13.

12 Shapiro GC, Christie DL. Gastroesophageal reflux and asthma. Clin Rev Allergy 1983;1:39-56.

13 Hoyoux C, Forget P, Lambrechto L. Chronic bronchopulmonary disease and gastroesophageal reflux in children. monary disease and gastroesopha

14 Buts JP, Barudi C, Moulin D, Claus D, Cornu G, Otte JB Prevalence and treatment of silent gastro-oesophageal reflux in children with recurrent respiratory disorders. Eur F Pediatr 1986;145:396-400.

15 Orenstein SR, Orenstein DM. Gastroesophageal reflux and respiratory disease in children. $\mathcal{F}$ Pediatr $1988 ; 112: 847-58$

16 Martin ME, Grunstein MM, Larsen GL. The relationship of gastroesophageal reflux to nocturnal wheezing in children with asthma. Ann Allergy 1982;49:318-22.

17 Boulton TJC, Rowley MP. Incidental observations of temperament, habits and

18 Lenney W, Milner AD. At what age do bronchodilator drugs work? Arch Dis Child 1978;53:532-5.

19 Lenney W, Milner AD. Alpha and beta adrenergic stimulants in bronchiolitis and wheezy bronchitis in children under 18 in bronchiolitis and wheezy bronchitis in childre

20 Strobel CT, Byrne WJ Ament ME, Euler AR. Correlation of oesophageal length with height: application to the Tuttle test without prior oesophageal manometry. 7 Pediatr 1979; 94:81-4.

21 Johnson LF, Demeester TR. Development of the twentyfour hour intraoesophageal $\mathbf{p H}$ monitoring composite scoring system. 7 Clin Gastroenterol 1986;8(suppl 1):52-8.

22 Vandenplas Y, Sacre-Smits L. Continuous 24 hour pH monitoring in 285 asymptomatic infants $0-15$ months old. f Pediatr Gastroenterl Nutr 1987;6:220-4.

23 Boix-Ochoa J, Lafuente JM, Gil-Vernet JM. Twenty-four hour esophageal $\mathrm{pH}$ monitoring in gastroesophageal reflux. $\mathcal{f}$ Pediatr Surg 1980;15:74-8.

24 Cucchiara S, Staiano A, Gobio Casali L, Boccieri A, Paone F. Value of the 24-hour intra-oesophageal $\mathrm{pH}$-monitoring in children. Gut 1990;31:129-33.
25 Stocks J, Levy NM, Godfrey S. A new apparatus for the accurate measurement of airway resistance in infancy. J Appl Physiol 1977;43:155-9.

26 Taussig LM, Landau LI, Godfrey S, Arad I. Determinants of forced expiratory flows in newborn infants. $\mathcal{F}$ Appl Physio 1982;53:1220-7.

27 Silverman M, Prendiville A, Green S. Partial expiratory flowvolume curves in infancy: technical aspects. Bull Eur Physiopathol Respir 1986;22:257-62.

28 Dubois AB, Botelho SY, Bedell GN, Marshall R, Comroe $\mathrm{JH}$. A rapid plethysmographic method for investigating thoracic gas volume: a comparison with a nitrogen washout method for measuring functional residual capacity in normal subjects. I Clin Invest 1956;35:322-6.

29 Stocks J, Godfrey S. Specific airways conductance in relation to post-conceptual age during infancy. 7 Appl Physiol 1977 43:144-54.

30 Beardsmore CS, Godfrey S, Silverman M. Forced expiratory flow volume curves in infants and young children. Eur Respir f 1989;2(suppl 4):154s-9s.

31 Vandenplas Y, Malfroot A, Dab I. Oesophageal pH monitoring criteria in infants with recurrent respiratory disease. Pediatr Res 1988;24:417.

32 Spaulding HS, Mansfield LE, Stein MR, Sellner JC Gremillion DE. Further investigation of the association between gastroesophageal reflux and bronchoconstriction. 7 Allergy Clin Immunol 1992;69:516-21.

33 Wilson NM, Charette L, Thomson AH, Silverman M Gastro-oesophageal reflux and childhood asthma: the acid test. Thorax 1985;40:592-7.

34 Herve $\mathbf{P}$, Denjean A, Jian R, Simonneau G, Duroux $\mathbf{P}$. Intraoesophageal perfusion of acid increases the bronchomotor response to methacholine and to isocapnic hyperventilation in asthmatic subjects. Am Rev Respir Dis 1986 ; 134:986-9.

35 Mansfield L, Stein MR. Gastroesophageal reflux and asthma- a possible reflex mechanism. Ann Allergy 1978;41 asthma

36 Mansfield L, Hameister H, Spaulding H. Smith NJ, Glab N. The role of the vagus nerve in airway narrowing caused by intraoesophageal hydrochloric acid provocation and oesophageal distension. Ann Allergy 1981;47:431-4.

37 Davis RS, Larsen GL, Grunstein MM. Respiratory response to intraoesophageal acid in asthmatic children. $\mathcal{f}$ Allergy Clin Immunol 1983;72:393-8.

38 Foglia RP, Fonksalrud EW, Ament ME. Gastroesophagea fundoplication for the management of chronic pulmonary disease in children. Am $\mathcal{F}$ Surg 1980;140:72-9.

39 Boyle JT, Tuchman DN, Altschuler SM, Nixon TE, Pack AI, Cohen S. Mechanisms for the association of gastrooesophageal reflux and bronchospasm. Am Rev Respir Dis 1985;131:s16-20.

40 Sindel BD, Maisels MJ, Ballantine TVN. Gastro-oesophageal reflux to the proximal oesophagus in infants with bronchoreflux to the proximal oesophagus in infants with broncho-

pulmonary dysplasia. Am 7 Dis Child 1989;143:1103-6.
Heyman S, Kirkpatrick JA, Winter HS, Treves S. An improved radionuclide method for the diagnosis of gastrooesophageal reflux and aspiration in children (milk scan). Radiology 1979;131:479-82.

42 Staugas R, Martin AJ, Binns G, Stevens IM. The significance of fat-filled macrophages in the diagnosis of aspiration associated with gastro-oesophageal reflux. Aust Paediat 7 1985;21:275-7.

43 Chakraborty TK, Ogilvie AL, Heading RC, Ewing DJ. Abnormal cardiovascular reflexes in patients with gastrooesophageal reflux. Gut 1989;30:46-9.

44 Axelrod FB, Maayan C, Hazzi C, Bangaru BS, Shannon DC. Bradycardia associated with hiatal hernia and gastroesophageal reflux relieved by surgery. Am $\mathcal{F}$ Gastroenterol $1987 ; 82$. 159-61. 